\title{
EXPERIMENTAL ANALYSIS OF AN S809 AIRFOIL
}

\author{
A. O. Gomes ${ }^{\mathrm{a}}$, \\ R. F. Brito ${ }^{b}$, \\ H. M. P. Rosa ${ }^{a}$, \\ J. C. C. Campos ${ }^{\mathrm{a}}$, \\ A. M. B. Tibiriça ${ }^{a}$, \\ and P. C. Treto \\ ${ }^{a}$ Universidade Federal de Viçosa \\ Departamento de Engenharia de \\ Produção e Mecânica \\ Av. PH Rolfs, s/n \\ Viçosa, Minas Gerais, Brasil \\ julio.campos@ufv.br \\ ${ }^{\mathrm{b}}$ Universidade Federal de Itajubá, \\ Campus Avançado \\ Departamento de Engenharia Mecânica \\ Itajubá, Minas Gerais, Brasil \\ ${ }^{\mathrm{c}}$ University of Costa Rica \\ Instituto de Investigaciones en Ingeniería \\ Montes de Oca, Costa Rica \\ Received: October 29, 2014 \\ Revised: November 30, 2014 \\ Accepted: December 30, 2014
}

\section{ABSTRACT}

This paper looks into the aerodynamic behavior of an S809 airfoil commonly utilized in wind turbines. Tests were carried out to measure drag coefficient profiles under high speed flows of up to $14 \mathrm{~m} / \mathrm{s}$, with Reynolds numbers ranging between approximately $\operatorname{Re}=11,400$ and $\operatorname{Re}=135,400$. The prototype was fabricated on a fused deposition modeling machine with ABS Plus thermoplastic. Several tests were carried out in a wind tunnel. Angles of attack ranging from $0^{\circ}$ to $20^{\circ}$ were tested in increments of two degrees in both the clockwise (leading edge above trailing edge) and counterclockwise directions (leading edge below trailing edge). Drag coefficient versus Reynolds number curves were obtained for the aforementioned angles. The airfoil drag coefficient was found to decrease as the Reynolds number increased for all the angles of attack analyzed. Airfoil dynamic stall was determined (maximum lift coefficient). In the tests, dynamic stall occurred at approximately $16^{\circ}$ clockwise. This value is in agreement with the literature.

Keywords: S809 airfoil, drag coefficient, Reynolds number, angle of attack

\section{NOMENCLATURE}

A the planform area of the airfoil, $\mathrm{m}^{2}$, Eq.(3)

c length of the chord, $m$

$\mathrm{C}_{\mathrm{d}} \quad$ drag coefficient, dimensionless, Eq.(2)

$\mathrm{Fd}$ drag force, $\mathrm{N}$

$l \quad$ width of the airfoil, $\mathrm{m}$

$\mathrm{R}_{\mathrm{e}}$ Reynolds number based on length of the chord, Eq.(1)

\section{Greek symbols}

$\begin{array}{ll}\alpha & \text { angle of attack, degrees } \\ \nu & \text { fluid kinematic viscosity, } \mathrm{m}^{2} / \mathrm{s} \\ \rho & \text { density, } \mathrm{kg} / \mathrm{m}^{3}\end{array}$

\section{INTRODUCTION}

Wind turbines were first used to produce electricity in the twentieth century, in response to accelerated economic growth and increased power consumption. Today, wind energy is highly desirable for being a non-polluting and theoretically inexhaustible mode of power generation. Another relevant factor is the strong ecological appeal present in wind energy generation, often listed as a requirement in current projects.

Researchers from all over the globe have been studying sustainable development and looking into alternative energy sources. Wind, and particularly wind turbines used for purposes of power generation, has been considered as one of the means to mitigate the use of fossil fuels. With that in mind, Alves (1997), Rasila (2003), and ChenWu et al. (2011) have studied wind turbines and analyzed the performance of rotors and variables such as torque, blade velocity control, and the effect of roughness on airfoil performance.

Burton et al. (2001), Epaarachchi and Clausen (2006), and Eggleston and Stoddard (1987) have focused their studies in the engineering design of wind turbines.

Ebert and Wood (1997) and Wright and Wood (2004) have found that when the Reynolds number increased from $1 \times 10^{4}$ to $1 \times 10^{5}$ in the initial stage of a $500 \mathrm{~W}$ wind turbine, the angle of attack gradually decreased from 86 to 20 degrees. Wang (2005) 
reported this finding when analyzing the flight of insects.

Sheng et al. (2009) presented results for the aerodynamic characteristics of the airfoil S809 for unsteady state condition.

Zhou et al. (2010) discussed the NACA0012 airfoil for a wide range of angles of attack, and described a drop in lift and a jump in drag force when the Reynolds number was in the $10^{4}$ range. The author further emphasized that the issues arising from a low Reynolds number have not been sufficiently addressed in the literature, much less when combined with high angles of attack.

Airfoil aerodynamics research appears to be more concentrated on conventional aircraft design with Reynolds numbers above $5 \times 10^{5}$ and below stall conditions.

Countless aerodynamic profiles have been proposed as a result of the intense efforts made by the scientific community to improve the efficiency with which wind power is used. However, special attention is required when the S809 airfoil is considered, as it has been designed to operate in turbines at low speeds.

In this context, the development of an experimental project on the S809 airfoil is justified. The main purpose is to assess airfoil aerodynamic performance at various angles of attack.

\section{MATHEMATICAL FORMULATION}

The equations used in this work for the calculation of Reynolds number and the drag coefficient are, respectively, according to Çengel (2007):

$$
\begin{gathered}
R_{e}=\frac{V c}{v} \\
C_{d}=\frac{F_{d}}{\frac{1}{2} \rho V^{2} A}
\end{gathered}
$$

where $\rho$ is the density of the air, $\mathrm{kg} / \mathrm{m}^{3}$, at ambient temperature, $\mathrm{K}, \mathrm{V}$ is air velocity, $\mathrm{m} / \mathrm{s}, \mathrm{c}$ is the length of the chord, $\mathrm{m}, \mathrm{v}$ the kinematic viscosity of the air, $\mathrm{m}^{2} / \mathrm{s}, \mathrm{Fd}$ the drag force, $\mathrm{N}$, and A the planform area of the airfoil, $\mathrm{m}^{2}$. The planform area of the airfoil is calculated as follows:

$$
A=c \times l
$$

where $l$, is the width of the airfoil, $\mathrm{m}$.

\section{EXPERIMENTS}

The profile presented in this paper belongs to S809 airfoils used in wind generators. Profile definitions, sizes, specifications, and curves have been described by Somers (1994). Figure 1 illustrates the profile of an S809 airfoil. An airfoil with a $150 \times 10^{-3} \mathrm{~m}$ chord was used in this study. This chord size was chosen due to wind tunnel size limitations.

\section{S809 Airfoil}

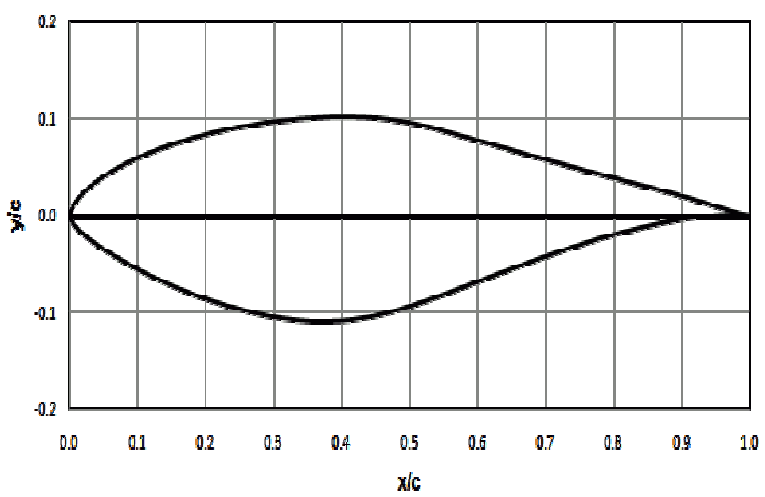

Figure 1. The profile of an S809 airfoil.

Modeling package SolidWorks was used to define the curves in the S809 profile, Fig. 1, along with the width of the prototype set at approximately $100 \times 10^{-3} \mathrm{~m}$. Figure 2 shows the curve generated with the aid of the SolidWorks software package.

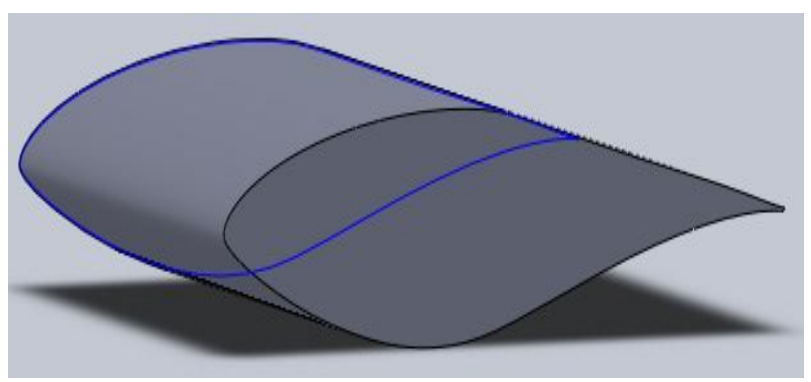

Figure 2. Model generated with the aid of the SolidWorks package.

In order to analyze the effect of weight on the model depicted in Fig. 2, a hollow model was built to assess airfoil cost-effectiveness (Fig. 3).

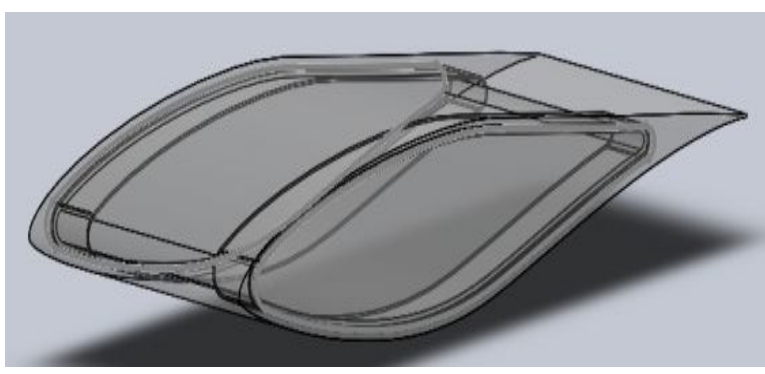

Figure 3.Model of the prototype shell.

The S809 model was fabricated on the prototyping machine available at the Department of Industrial and Mechanical Engineering. The model is shown in Figure 4. 


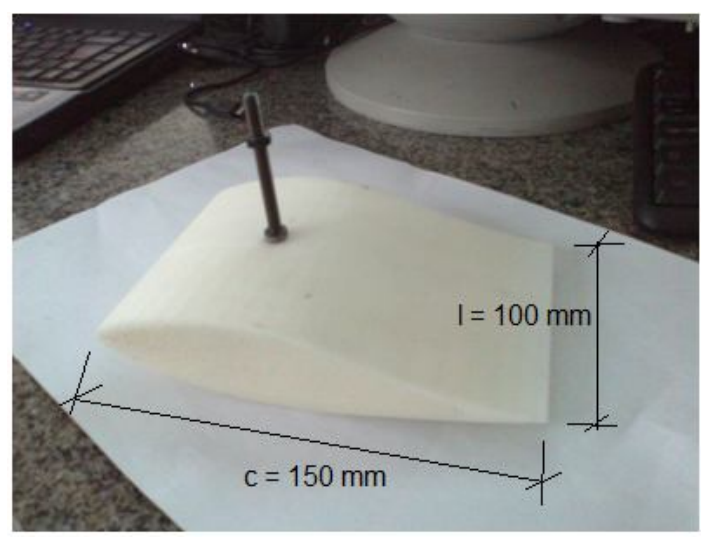

Figure 4. Airfoil equipped with wind tunnel attachment pin (chord and width measurements).

The model was built with thermoplastic ABS PLUS, a material $40 \%$ stronger than regular ABS. The properties of this material are described in the prototyping machine literature.

This paper aimed to measure drag coefficients as a function of Reynolds numbers for an S809 airfoil profile in a range of angles of attack in the clockwise and counterclockwise directions, for wind speeds between 0 and $14 \mathrm{~m} / \mathrm{s}$ with a standard error of $1 \mathrm{~m} / \mathrm{s}$.

The blockage effect of the airfoil at large $\alpha$ in the wind tunnel was corrected based on Maskell (1963). The value of the blockage effect, in a wind tunnel, was 0.092 .

Other factors such as static pressure gradient and the boundary layer effects were not considered. Wind tunnel free-stream turbulence level could not be measured, as a hot-wire anemometer was not available. The Aerostream Wind Tunnel shown in Figure 5 was used for the purposes of this study.

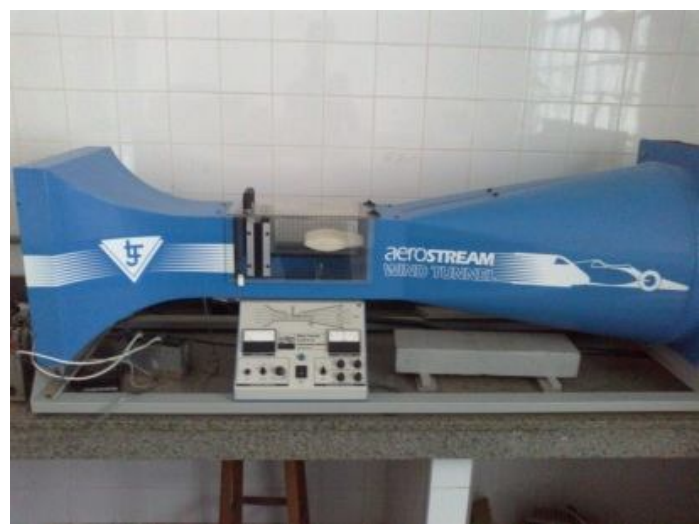

Figure 5. The wind tunnel located at UFV.

The S809 airfoil model was attached to the wind tunnel with the aid of a free moving pin (Fig.5). Test sessions were carried out with angles of attack ranging from $0^{\circ}$ to $20^{\circ}$. The angle of attack was reset in increments of two degrees in the clockwise and counterclockwise directions. In the clockwise direction, the leading edge was above the trailing edge, while the opposite was true for the tests run in the counterclockwise direction.

Measurements were made with alternating angles of attack, i.e., drag forces were first measured in one direction at a certain angle and then in the opposite direction at the same angle. This method precludes the occurrence of testing systematic error. The angles were measured with a Mitutoyo goniometer, with a minimum resolution of $1^{\circ}$. Figure 6 illustrates the measurement procedure.

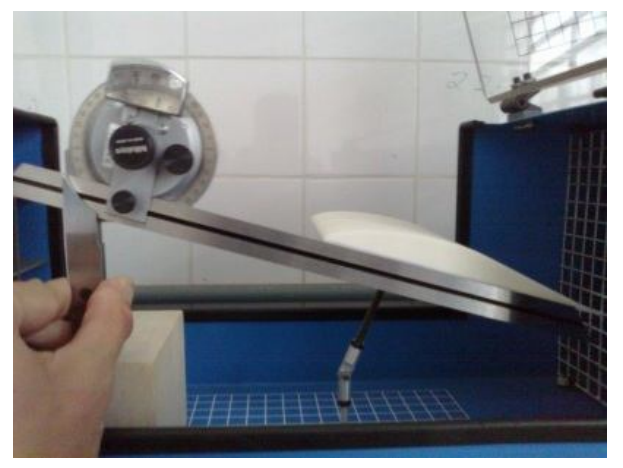

Figure 6. Method used to measure airfoil angles of attack (clockwise direction).

Figure 7(a,b) shows how the angle of attack was reset by adjusting the free moving pin and the airfoil front and upper views in the wind tunnel test.

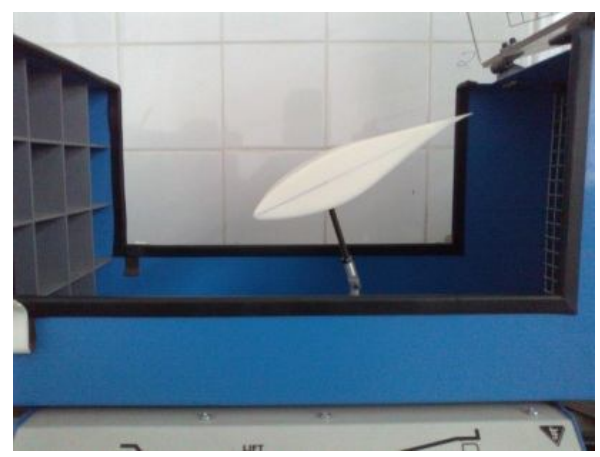

(a)

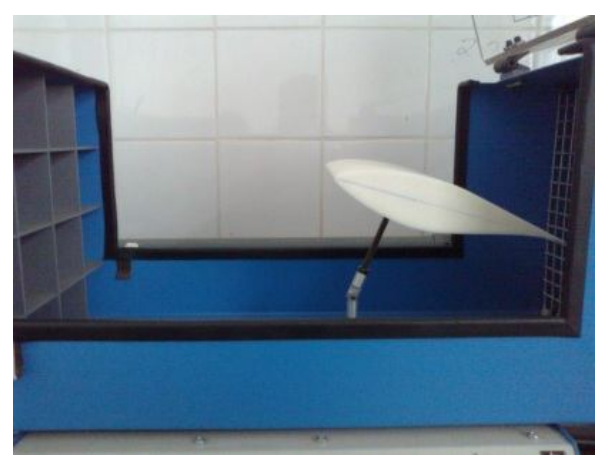

(b)

Figure 7. Angle of attack directions: (a) counterclockwise, (b) clockwise. 


\section{RESULTS AND DISCUSSION}

The results presented in this paper refer to the drag coefficient versus Reynolds number plots at various angles of attack. These experimental results were obtained with the aid of a wind tunnel.

Figure 8 shows the behavior of experimental drag coefficient $\mathrm{Cd}$ as a function of angle of attack $\alpha$, for $\operatorname{Re}=121,200$. It also depicts the dependence between drag coefficient and angle of attack. The horizontal axis of the graph in this Figure represents a clockwise angle of attack with a positive signal. In the graph, the maximum value for $\mathrm{Cd}$ is approximately 0.12 .

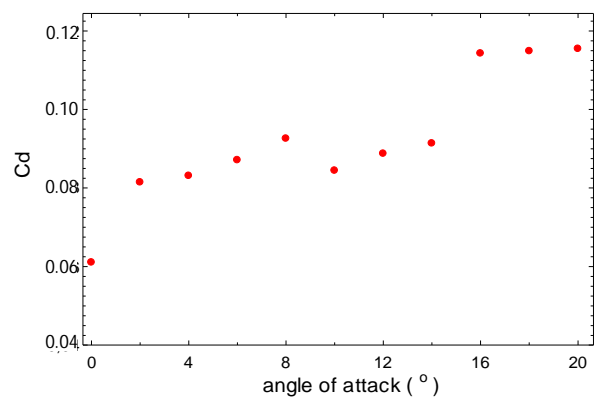

Figure 8. Drag coefficient versus angle of attack, $\operatorname{Re}=121,200$.

The experimental results of the Cd versus $\alpha$ plot for $\operatorname{Re}=10^{6}$ presented by Gharali and Johnson (2012) were similar to the results reported in Figure 8. The maximum value found for $\mathrm{Cd}$ was observed at an angle of $16^{\circ}$.

Figure 8 reveals that when the Reynolds number is high, $\mathrm{Cd}$ values tend to manifest along a horizontal straight line. Therefore, high-speed wind flows tend to make the drag coefficient constant regardless of airfoil angle of attack. This can be verified for $\alpha$ values from $2^{\circ}$ to $8^{\circ}$, followed by a slight oscillation at angles between 8 and 10 degrees, only to become constant again in the $10^{\circ}$ to $14^{\circ}$ range, then some more oscillation from $14^{\circ}$ to $16^{\circ}$, and finally a constant drag coefficient from $16^{\circ}$ to $20^{\circ}$.

The figure 8 highlights the aerodynamics of S809 airfoil dependent appreciably of $\alpha<20^{\circ}$, but very slightly or negligibly at $\alpha>20^{\circ}$. In this Figure, $\mathrm{Cd}$ increases monotonously with $\alpha$ and reaches the maximum at $\alpha \approx 16^{\circ}$. The inflection point of $\mathrm{Cd}$ occurs at $\alpha \approx 8^{\circ}$.

The Figures 8 and 9 shows at the small $\alpha$, i.e., $\alpha$ $<8^{\circ}$ there is no a jump in $\mathrm{Cd}$, suggesting the absence of the stall that is associated with an airfoil wake of $\operatorname{Re} \geq 100 \times 10^{3}$.

The Figure 9 shows the $\mathrm{Cd}$ versus Reynolds number plot with $\alpha$ ranging from $4^{\circ}$ to $16^{\circ}$. The graph indicates that, regardless of $\alpha, \mathrm{Cd}$ decreases as the Reynolds number increases. Additionally, at high Reynolds numbers Cd remains constant, as seen in Fig.8. Another noteworthy finding is that the drag coefficient remains close to constant when the
Reynolds number is greater than $100 \times 10^{3}$, possibly characterizing the transition between laminar and turbulent flow.

The Reynolds number is one of the control parameters for flow around the airfoil, and to a certain extent Cd and CL, (Zhou et al., 2011).

In this Figure, the first $\alpha$ is near the stall and the second corresponds to the maximum $\mathrm{Cd}$. The third and the fourth are distant from the peak.

In the figure $9(\mathrm{a}, \mathrm{b}), \mathrm{Cd}$ vary little for $\mathrm{Re} \approx$ $100 \times 10^{3}-140 \times 10^{3}$ or $10 \times 10^{4}-14 \times 10^{4}$ where the separation point occurs near the leading edge.

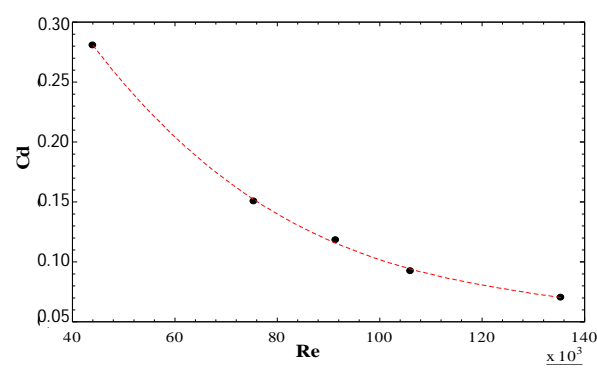

(a)

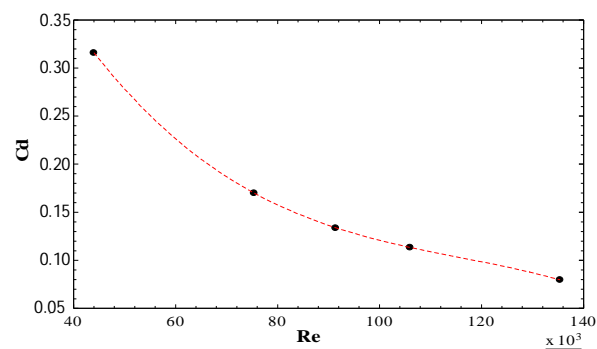

(b)

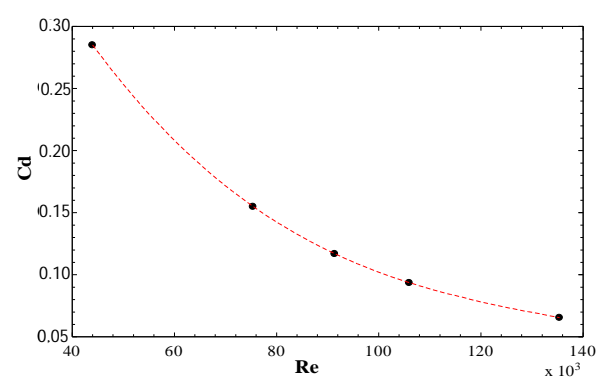

(c)

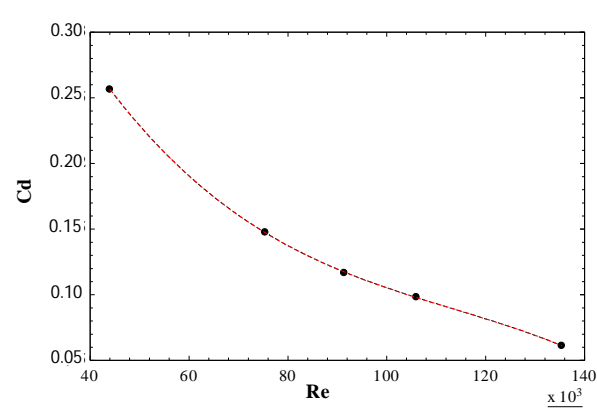

(d)

Figure 9. Drag coefficient versus Reynolds number, (a) $\alpha=12^{\circ}$; (b) $\alpha=16^{\circ}$; (c) $\alpha=4^{\circ}$; (d) $\alpha=8^{\circ}$. 
A similar variation in $\mathrm{Cd}$ with $\mathrm{Re} \approx 1.05 \times 10^{4}$ $2 \times 10^{5}$ has been well documented in a $2-\mathrm{D}$ circular cylinder wake at Re. In this condition, the boundary layer around the surface is laminar but the separated shear layer is turbulent, the flow separation point is almost independent of Re (Zhou et al., 2011). Thus, the corresponding $\mathrm{Cd}$ varies little with $\mathrm{Re}$. This finding was verified in figs. $9(\mathrm{a}, \mathrm{b})$ for $\mathrm{Re} \approx 100 \times 10^{3}$ $-140 \times 10^{3}$ or $10 \times 10^{4}-14 \times 10^{4}$.

\section{CONCLUSIONS}

The aerodynamic characterization of airfoil profiles should include smaller angles of attack, particularly of 20 degrees. Aerodynamic performance may be significantly affected, as important drag forces act on the airfoil in this angle of attack range. This was described by Zhou et al. (2011).

The drag coefficient increases as the angle of attack is increased in the clockwise or counterclockwise direction. However, as previously described, drag gain is higher in the counterclockwise direction. For a fixed angle, the drag coefficient drops even as drag forces increase. This occurs when the Reynolds number increases, i.e., as speed increases.

As the Reynolds number increases, the drag coefficient tends to manifest along a horizontal straight line. Therefore, high-speed wind flows make the drag coefficient tend to a constant value, regardless of the airfoil angle of attack. This characterizes the transition between laminar and turbulent flow zones.

\section{ACKNOWLEDGEMENTS}

The authors would like to thank FAPEMIG for the financial support provided.

\section{REFERENCES}

Alves, A. S. G., 1997, Análise do Desempenho de Rotores Eólicos de Eixo Horizontal, Master Thesys, Universidade Federal do Pará, Brasil. (in Portuguese)

Burton, T., Sharpe, D., Jenkins, N., and Bossanyi, E., 2001, Wind energy: handbook. Ed., John Wiley \& sons, Inglaterra.

ChenWu, H., Ke, Y., Qiang, L., Lei, Z., JingYan, B., and JianZhong, X., 2011, A Study on Performance Influences of Airfoil Aerodynamic Parameters and Evaluation Indicators for the Roughness Sensitivity on Wind Turbine Blade, Institute of Engineering Thermophysics, Chinese Academy of Sciences, Beijing 100190, China.

Çengel, Yunus, A., Cimbala, and John, M., 2007, Mecânica dos fluidos: Fundamentos $e$ aplicações, $4^{\mathrm{a}}$ Ed., McGraw Hill, 584p. (in Portuguese)

Ebert, P. R., and Wood, D. H., 1997, Observations of the Starting Behavior of a Small
Horizontal-Axis Wind Turbine, Renew. Energy, Vol. 12, pp. 245-257.

Eggleston, D. M., and Stoddard, F. S., 1987, Wind Turbine Enginering Design, Van Nostrand Reinhold Company, New York.

Epaarachchi, J. A., and Clausen, P. D., 2006, The Development of a Fatigue Loading Spectrum for Small Wind Turbine Blade, Journal of Wind Engineering and Industrial Aerodynamics, pp. 207223.

Gharali, K., and Johnson, D. A., 2012, Numerical Modeling of an S809 Airfoil under Dynamic Stall, Erosion and High Reduced Frequencies, Applied Energy, Vol. 93, pp. 45-52.

Maskell, E. G., 1963, Theory of Blockage Effects on Bluff Bodies and Stalled Wings in a Closed Wind Tunnel, ARC R\&M 3400.

Rasila, M., 2003, Torque and Speed Control of a Pitch Regulated Wind Turbine, Master Thesis, University of Technology, Göteborg, Sweden.

Sheng, W, Galbraith, McD., and Coton, F., 2009, On the S809 Airfoil's Unsteady Aerodynamic Characteristics, Wind Energy.

Sommers, D., 1994, Design and Experimental Results for S809 Airfoil, NREL/SR-440-6918.

Zhou, Y., Md., Mahbub, Alam, Yang, H. X., Guo, H., and Wood, D. H., 2011, Fluid Forces on a Very low Reynolds Number Airfoil and their Prediction, Schulich School of Engineering, University of Calgary, Canada.

Wang, Z. J., 2005, Dissecting Insect Flight, Annu. Rev. Fluid Mech, Vol. 37, pp. 183-210.

Wright, A. K., and Wood, D. H., 2004, The Starting and Low Wind Speed Behavior of a Small Horizontal Axis Wind Turbine, Journal of Wind Engineering and Industrial Aerodynamics, Vol. 92, pp. 1265-1279. 